Андрей Сычев

\title{
СОЦИАЛЬНАЯ ПОЛИТИКА В УСЛОВИЯХ ПРОБЛЕМАТИЗАЦИИ ПРАВ ЧЕЛОВЕКА
}

\section{McCann G., hAdhmaill F.ó (eds.) (2020) International Human Rights, Social Policy and Global Development. Bristol: Policy Press. 294 p. ISBN 9781447349211.}

\author{
DOI: $10.17323 / 727-0634-2020-18-2-368-372$
}

За время, которое прошло со времени принятия Всеобщей декларации прав человека, на международном уровне были разработаны и ратифицированы многочисленные нормативные документы, закрепившие разные группы прав и определившие особенности их реализации применительно к уязвимым социальным группам (детям, женщинам, мигрантам). Параллельно создавались и совершенствовались межгосударственные механизмы защиты прав человека, включающие комитеты, комиссии, суды и пр. Сегодня права человека повсеместно признаны правовым, идеологическим и моральным каркасом современного миропорядка: к ним апеллируют как к последней инстанции значимые акторы социальной политики.

Права человека декларируются как самоочевидные, общепризнанные, абсолютные и универсальные. Однако попытки разобраться в их конкретном содержании неизменно демонстрируют, что в реальности по их поводу нет ни уверенности, ни согласия. Как теория прав человека, так и практика их защиты до сих пор предоставляют множество поводов для споров и конфликтов. Особенно явно их неоднозначность и хрупкость проявляется в условиях обострения социальных проблем, переводящих общественную систему в чрезвычайный режим: войн и вооруженных конфликтов, терроризма, природных и техногенных бедствий. Реальность, с которой ежедневно сталкивается большая часть человечества, все еще очень далека от ожиданий авторов Всеобщей декларации, и выяснение причин этого несоответствияодин из важных вопросов на повестке дня теории социальной политики.

Коллективная монография «Международные права человека, социальная политика и глобальное развитие» предлагает критический анализ проблем социальной политики в контексте вызовов, стоящих перед правами человека. Авторы представляют различные страны, их исследовательские интересы многообразны (социальная политика, политология, право, международные отношения, история). Несмотря на это, книга

Андрей Анатольевич Сычев- д.ф.н., профессор, кафедра философии, Национальный исследовательский Мордовский государственный университет, Саранск, Россия. Электронная почта: sychevaa@mail.ru 
воспринимается как целостное исследование. Все ее главы написаны в едином стиле, доступно, сжато и информативно. Авторы последовательно выражают критическую позицию по отношению к господствующему дискурсу по поводу прав человека. Фокусируясь на проблемных точках, как теории, так и практики прав человека, они выявляют недостатки и пробелы в инструментах их защиты. И в то же время пытаются очертить и те преимущества, которые эти инструменты могут предоставить неправительственным организациям, сообществам и отдельным людям, готовым к борьбе против несправедливости и дискриминации.

Авторов книги объединяет стремление рассматривать права человека не в виде готового набора положений, а динамичного процесса, характер которого зависит от изменений в обществе и от деятельной позиции людей по отношению к этим изменениям. В предисловии, написанном для монографии известным правозащитником Алби Саксом, эта позиция выражается так: «Универсальные права человека не суть нечто данное нам богами или природой: они являются творением человеческой свободы, воображения, креативности, человечности, и, самое важное- борьбы» (Р. 11).

В книге три части, разбитые на двадцать глав. Первая часть «Международные права человека: контекст» посвящена в основном описанию становления и развития прав человека. Она открывается кратким обзором предыстории вопроса: от возникновения представлений о правах как таковых до появления и развития идеи прав человека в Новое время. Особое внимание уделяется деятельности ООН по созданию и уточнению законодательства в области прав человека, рассматриваются базовые нормативные документы в этой области. Представлен краткий обзор конвенций: от ратифицированной всеми странами-членами ООН, кроме США, Конвенции о правах ребенка до не ратифицированной ни одним «развитым» государством Международной конвенции о защите прав всех трудящихся-мигрантов и членов их семей.

Процесс нормативного оформления прав человека показан как результат геополитических маневров эпохи холодной войны, в которой Западный блок поддерживал негативные (гражданские, политические права и свободы), а Восточный, соответственно- позитивные (социально-экономические) права. После окончания идеологического противостояния на повестку дня вышли вопросы «третьего поколения»- коллективных прав (Р. 22).

Рассмотрены механизмы защиты прав человека в Европейском совете, Европейском союзе и США, при этом авторы фокусируются на проблемных и слабых местах этих механизмов. Показателен в этом аспекте анализ состояния с правами человека в США: скрупулезно перечисляются нарушения в этой сфере, наглядно демонстрирующие разрыв, лежащий между декларациями и реальными действиями. Завершается глава обзором международного гуманитарного права в контексте современных вооруженных конфликтов. 
Во второй части «Ключевые вопросы подходов, основанных на всеобщих правах человека» рассмотрены проблемы реализации прав человека, а также сильные и слабые места имеющихся инструментов их защиты. Здесь анализируется роль ЕС как ключевой движущей силы процесса международного развития. В то же время, как показывают авторы, реальные действия стран членов-ЕС далеко не всегда соответствуют идеям развития партнерства и универсальности прав человека. Прежде всего, они ориентированы на укрепление экономических и политических позиций, удерживание развивающихся стран в сфере своего влияния, а также защиту «Крепости-Европы» от нежелательных мигрантов.

Авторы подробно описывают социально-экономические права (на достаточный жизненный уровень, труд, социальное обеспечение) и вызовы им, а также культурные права (на участие или неучастие в культурной жизни, наслаждение искусством и использование результатов научного прогресса, образование) и причины небрежения ими. Отмечается, что культурные права, предполагающие многообразие и тесно связанные с этничностью, религиозностью сами по себе являются вызовом универсальности (Р. 122).

Защита прав становится наиболее проблематичной на фоне миграции, вооруженных конфликтов и гендерных отношений. Миграция описана как наиболее слабое место в системе прав человека (особенно в современном развитом обществе, демонстрирующем негативное отношение к иммигрантам и беженцам). Проблемы с соблюдением прав человека наблюдаются и во время разного рода внутренних конфликтов, где государства обычно предпочитают не пользоваться словом «война» и именуют противников «бандформированиями» или «террористами», выводя их тем самым за границы гуманитарного права (Р. 142). Показывается, как повсеместно нарушаются права человека под предлогом борьбы с терроризмом, который остается весьма туманным и субъективно трактуемым понятием. Оканчивается вторая часть критикой универсализма с феминистских позиций.

В завершающей части «Подходы, основанные на правах человека, к развитию и социальной политике» проблематизируются права на образование, здравоохранение, жилище, а также права детей, людей с ограниченными возможностями. Венчается книга обзором права на развитие, при этом права и развитие рассматриваются в качестве двух сторон одного явления.

Особо показательна для понимания специфики этой части монографии (как и общего замысла всей книги в целом) глава, посвященная людям с инвалидностью. Здесь структурные элементы, составляющие главы об объектах социальной политики, представлены в наиболее полном и последовательном виде (в прочих главах некоторые из них могут быть опущены). Так, здесь описываются традиционные подходы к проблеме; очерчивается специфика подхода, основанного на правах человека; раскрываются правовые механизмы обеспечения этого подхода; рассматривается практика 
реализации прав. Люди с ограниченными возможностями-самое многочисленное меньшинство, сталкивающееся с серьезными проблемами при реализации своих прав. Решение их проблем традиционно опиралось на оказание медицинской помощи, а затем на снятие барьеров, препятствующих нормальной жизни.

Подход с позиции прав представляет собой своеобразный синтез предшествующих представлений: он не просто предполагает снятие барьеров, но и накладывает обязанность предоставить таким людям возможности реализовывать свои права наравне со всеми остальными. Так, если для участия ряда групп (например, женщин) в выборах достаточно снятия законодательных барьеров, то для инвалидов нужно создать условия для участия (организовать голосование на дому, сделать трафареты и пр.). Фактически в этом контексте негативные права приобретают позитивное выражение (Р. 243). Наконец, сами инвалиды должны стать равноправными субъектами нормотворческой и правореализующей деятельности, а не объектами благотворительности и патерналистской заботы государства. В этом смысле справедливость по отношению к людям с ограниченными возможностями основывается не столько на распределении благ, сколько на равном участии: «Ничего о нас без нас» (см., Appiah et al. 2007). Инвалиды должны иметь возможность самостоятельно обговаривать и принимать решения по вопросам, которые их заботят. Глава завершается описанием успешной борьбы (с опорой на Конвенцию по правам инвалидов) за перераспределение выделяемых ЕС фондов от учреждений социальной защиты к локальным сообществам, самостоятельно решающим, как им их тратить.

В целом права человека в монографии представлены как конституирующие элементы современной цивилизации, позволяющие сбалансировать требования справедливости и свободы. Однако, как наглядно показывает критический обзор, эти права могут стать объектом нарушений и злоупотреблений. Важным условием борьбы за права является гражданское участие. В этом контексте авторы говорят о необходимости движения от «слабой» (представительной) демократии к «сильной», где граждане активно вовлечены в процесс уточнения и реализации своих прав и готовы принимать ответственность за свою деятельность (Barber 1984).

На фоне современного политического дискурса по поводу прав человека, тяготеющего, на одном полюсе, к официозной декларативности, а на другом-к правому популизму, исследование воспринимается как попытка критично, без пафоса и неприятия, посмотреть на реальные проблемы в сфере прав человека. Тем не менее в книге имеются некоторые пробелы. Она, несомненно, выиграла бы, если бы авторы уделили больше внимания регионам за пределами США и Западной Европы, а также претензиям их представителей на создание перечня прав человека на основе альтернативных систем ценностей, трансформирующих режимы социальной политики (Jacobsen, Bruun 2000). Кроме того, желание предоставить 
исчерпывающую информацию по правам человека привело к тому, что материал более общего характера (сконцентрированный в первых двух частях) доминирует над рассмотрением конкретных вопросов социальной политики. Видимо поэтому за пределами книги остались право на отдых, права пожилых людей, права в условиях пандемии, экологического кризиса и многие другие. С имеющимся вводным заделом следовало изначально планировать или монографию большего объема или серию книг.

С другой стороны, обширное введение в проблему имеет и свои преимущества. Благодаря ему книга вполне может быть рекомендована в качестве пособия для студентов по различным курсам, посвященным правам человека и социальной политике (в таком случае ей не помешал бы дополнительный справочный аппарат в виде списка сокращений, перечня нормативных документов и инструментов их реализации). Кроме того, она, несомненно, будет полезна тем исследователям, которые интересуются правами человека в контексте социальной политики, международных отношений и этики.

Andrey Sychev

SOCIAL POLICY IN THE CONTEXT

OF HUMAN RIGHTS PROBLEMATIZATION

McCann G., hAdhmaill F.ó (eds.) (2020) International Human Rights, Social Policy and Global Development. Bristol: Policy Press. 294 p. ISBN 9781447349211.

DOI: $10.17323 / 727-0634-2020-18-2-368-372$

\section{References}

Barber B. (1984) Strong Democracy: Participatory Politics for a New Age. Berkeley: University of California.

Appiah K. A., Benhabib S., Young I. M., Fraser N. (2007) Justice, Governance, Cosmopolitanism, and the Politics of Difference. Berlin: Humboldt University.

Jacobsen M., Bruun O. (2000) Human Rights and Asian Values: Contesting National Identities and Cultural Representations in Asia. London. Routledge.

Andrey Sychev - Dr. Sci. (Philosophy), Professor, Department of Philosophy, National Research Mordovia State University, Saransk, Russian Federation. Email: sychevaa@mail.ru 